\title{
Decreases of regional cerebral oxygen saturation reading during hip arthroplasty associated with postoperative delirium in older adults
}

Guo-Jun Zhou ( $\sim$ zgj12011@sina.com )

Zhejiang University

Shao-Hua Yu

Zhejiang University

Zhu-Li Wang

Zhejiang University

Rong-Xin He

Zhejiang University

\section{Research Article}

Keywords: Postoperative delirium, Replacement, total hip, near-infrared spectroscopy

Posted Date: June 22nd, 2021

DOI: https://doi.org/10.21203/rs.3.rs-641628/v1

License: (ㄷ) (i) This work is licensed under a Creative Commons Attribution 4.0 International License. Read Full License 


\section{Abstract}

Background Postoperative delirium (POD) is a sign of deterioration in the homeostasis and physical status of the patient. However, there have been no reports regarding the relationship between the decrease of regional cerebral oxygen saturation $\left(\mathrm{rSctO}_{2}\right)$ reading during surgery and the POD in hip replacement in the elder. This study aims to investigate this correlation and the incidence of POD.

Methods We performed a retrospective study of 4834 patients who underwent hip arthroplasties between 2015 and 2019 at our hospital. Data were collected as part of routine patient care. The patients' cognitive performance was evaluated by using the Manual of Mental Disorders (DSM-IV-TR 4th edition) criteria. Patients found to be delirious after surgery served as the delirium group, other patients who did not develop delirium after surgery regarded as the no-delirium group. The various factors including the decline of $\mathrm{rSctO}_{2}$ reading intraoperatively were assessed using Multivariable logistic regression models. Odds ratio (OR) and 95\% confidence intervals $(\mathrm{Cl})$ are reported.

Results POD was found in 27 patients ( $n=351$ ); the incidence of POD was 7.7\%; all of them were in their 70's or 80's. Lab data and $\mathrm{rSctO}_{2}$ reading before surgery were no significantly difference between the delirium group and the no-delirium group. Patients who displayed the decline of $\mathrm{rSctO}_{2}$ reading intraoperatively were at higher risk for POD (compared with no-delirium patients: OR2.169 Cl 1.663-2.829 p=0.000) and gender (compared with no-delirium patients: OR $0.163 \mathrm{Cl}$ 0.029-0.909 $p=0.039$ ) was at a higher risk. Twenty-four patients recovered from POD gradually. One patient had persistent and severe cognitive dysfunction after surgery, two patients died of complications either acute pulmonary embolism 4 days after surgery or acute stroke 21 days after surgery respectively.

Conclusions The incidence of $\mathrm{POD}$ was $7.7 \%$. This study shows that the decline of $\mathrm{rSctO}_{2}$ reading during hip replacement surgery in the elder is associated with increased probability for the POD.

\section{Introduction}

Delirium is a syndrome of acute cerebral inefficiency affecting the brain in various ways. In a review [1], the incidence of POD was $13-41 \%$ in joint replacement surgery. Delirium creates an acute and fluctuating deleterious impairment of cognitive function that involves consciousness, attention, memory, perception, judgment, abstract thinking, orientation, and planning and organizational skills [2,3]. The symptoms of delirium can occur suddenly or slowly over a period of hours or days, and may be so slight that they go unnoticed or so serious that they could be life threatening. Although the etiology is not well understood, multiple risk factors for POD were described in previous studies, including: age [4], female sex [5,6], longer duration of surgery [6], choice of general anesthetics [7], imbalance of electrolyte [8], and use of intraoperative or postoperative drugs [9] (benzodiazepines or ketamine) and hypothermia [10], being operated on and kept in ICUs [11], infections [12], nutritional status identified by albumin level [13], pain [14], comorbidities [15-18] (such as hypothyroidism, renal dysfunction, diabetes, obesity, valvar disease, hypertension, congestive heart failure), withdrawal of alcohol [19], and psychosocial environment [20] (depression/anxiety or psychoses), and even subclinical cerebral damage [21], inability to ambulation [22], treatment with multiple drugs [13]. Preclinical and clinical research in recent years has uncovered more about the pathophysiology of POD and maybe yield some therapeutic options or effective perioperative intervention in order to reduce the prevalence of POD, but up to date, POD is still a common complication after major surgery in older patients and is becoming a great concern because of high incidence and a lengthy hospitalization period.

In past four years, the number of elderly patients needed total hip replacement has been increasing in our hospital. We have frequently encountered patients who have developed POD, and experienced a great deal of difficulty in postoperative care. Accidentally, we observed that some patients who showed the decline of $\mathrm{rSctO}_{2}$ reading 
intraoperatively suffered from delirium in elderly patients on postoperative day 1 or 2 . We hypothesize that the low value of $\mathrm{rSctO}_{2}$ intraoperatively was related with POD.

Cerebral Oximetry is a non-invasive optically based technology that measures regional cerebral tissue oxygen saturation $\left(\mathrm{rSctO}_{2}\right)$ [23]. Regional cerebral oximetry can provide an immediate indication of cerebral blood flow changes, oxygenation changes. The FORE-SIGHT® (CASMED, Branford CT USA) [24] cerebral oximeter can assess absolute rSctO $_{2}$ values based on total oxy- and deoxyhemoglobin concentration of cerebral tissue without the need for a pre-induction baseline. At the present time, cerebral oximetry [25] is the only feasible technology that monitors cerebral hypoxia and/or cerebral ischemia noninvasively and continuously. $\mathrm{rSctO}_{2}$ reflects the balance between cerebral oxygen consumption and supply, so intraoperative cerebral oxygen desaturation events were related with increased risk of stroke, adverse neurological outcomes, postoperative cognitive dysfunction, days of hospital stay and mortality.

There are three theories regarding the pathophysiology of postoperative delirium, which can interpret the possible mechanism of postoperative delirium. Neuro-inflammation theory [26], subclinical cerebral vascular events theory [27] and neurotransmitters theory [28], to a large extent, still are based on findings from animal models. However, evidence from human in vivo research is very currently limited. Basing on our hypothesis, the aim of this retrospective study is to explore the relationship between them.

\section{Methods}

\section{Study design and Patients}

We conducted a retrospective research of patients who underwent elective total hip arthroplasties at our hospital between April 1, 2015 and May 30, 2019. This study was approved by the Ethics Committee of our hospital (Ethical Committee number 201911) and was exempt from the requirement to obtain informed consent from patients because of the retrospective and observational study design. All data utilized for this study were collected as part of routine patient care.

Data of patients' demographics, medical history, comorbidities, symptoms, signs, diagnoses, and perioperative management were obtained from the patient electronical information system. Intraoperative management and Data were recorded in the anesthesia information system. Patients who had one of following abnormal findings before surgery were excluded from our study: (1) schizophrenia, epilepsy, Parkinsonism, myasthenia gravis, cerebrovascular disease, history of transient ischemic attack (TIA); (2) delirium or history of delirium; (3) abused psychoactive drugs and alcohol before surgery; (4) cerebral trauma; (5) American Society of Anesthesiologists (ASA) physical status >III; (6) high hepatic enzymes(glutamic-pyruvic transaminase $\left.>40 \mathrm{U}^{-\mathrm{L}^{-1}}\right)$, renal insufficiency or serum urea nitrogen $\left(>100 \mathrm{mg} \cdot \mathrm{dl}^{-1}\right)$;

(7)hypocalcemia ( $\left.<8 \mathrm{mg} \cdot \mathrm{dl}^{-1}\right)$, hypo/hypernatremia $\left(<130\right.$ and $\left.>150 \mathrm{mmol} \cdot \mathrm{l}^{-1}\right)$, hypo/hyperpotassemia $\left(<3\right.$ or $\left.>6 \mathrm{mEq} \cdot \mathrm{l}^{-1}\right)$; (8) Anemia (hemoglobin $<8 \mathrm{~g} \cdot \mathrm{dl}^{-1}$ ), hypoalbuminemia $\left(<3 \mathrm{~g} \cdot \mathrm{dl}^{-1}\right.$ ) and symptomatic infection (fever, $\left.>38^{\circ} \mathrm{C}\right)$; (9) usage of volatile anesthetic, Ketamine, benzodiazepines and dexmedetamidine during surgery were excluded. In addition, patients kept intubated and were transferred to the ICU after surgery were also eliminated.

Patients found to be delirious after surgery served as the delirium group (Delirium), other patients who did not develop delirium after surgery regarded as the no-delirium group (No Delirium)

\section{Anesthesia and Intraoperative Management}

Upon arrival at the operating room, a radial intra-arterial catheter, a bi-spectral index (BIS) monitor, and two CASMED electrodes (left and right forehead) were positioned besides the other routine monitors. Sufentanil 0.6-1 $\mu \mathrm{g} \cdot \mathrm{kg}^{-1} \mathrm{and}$ propofol 2-3mg $\mathrm{kg}^{-1}$ were used for anesthesia induction, all patients' tracheas were intubated and maintained with total intravenous anesthesia using propofol $70-150 \mu \mathrm{g} \cdot \mathrm{kg}^{-1} \cdot \mathrm{min}^{-1}$ and remifentanil $0.2-0.3 \mu \mathrm{g} \cdot \mathrm{kg}^{-1} \cdot \mathrm{min}^{-1}$ to target a BIS between 
40 and 60 (The depth of anesthesia). Volume-controlled ventilation was used with a tidal volume of 8-10 ml. $\mathrm{kg}^{-1} \mathrm{and} \mathrm{a}^{-1}$ respiratory rate of 8-10 breaths $\cdot \mathrm{min}^{-1}$ to target an end-tidal carbon dioxide between 35 and $40 \mathrm{mmHg}$. The inspired oxygen was $75 \%$. Muscle relaxation was maintained with rocuronium bromide. The value of intra-arterial pressure was kept above 90 percent of baseline by fluid infusion and the use of vasoactive agents during surgery. The scores of oxygen saturation by pulse oximetry $\left(\mathrm{SPO}_{2}\right)$ and end-tidal partial pressure of carbon dioxide $\left(\mathrm{PetCO}_{2}\right)$ were maintained by setting respirator parameter. Red blood cells were administered to increase hemoglobin levels $>10 \mathrm{~g} \cdot \mathrm{dl}^{-1}$. All of which were scored with the anesthesia information system in a real-time manner. Glycemic value was kept in 3.9-7 $\mathrm{mmol} \cdot \mathrm{L}^{-1}$ level by using insulin. Regional cerebral tissue oxygen saturation $\left(\mathrm{rSctO}_{2}\right)$ of all patients before general anesthesia and during

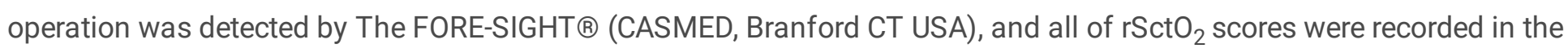
anesthesia information system by anesthesiologist in a real-time manner. All surgeries were carried out by three skillful hip surgeons. At the end of surgery, before skin suturing, the wound was completely infiltrated with $3 \mathrm{mg}^{\circ} \mathrm{kg}^{-1}$ of $0.375 \%$ ropivacaine ( $0.75 \%$ ropivacaine mixed with saline). Patients were transferred to the PACU for at least 30 min, and then to the general ward; otherwise, they were transferred to the ICU when needed.

\section{Perioperative Data}

Baseline data included patient characteristics (age, sex, and body mass index, education level, ASA class, past surgery history, past medication history) and preoperative comorbidities were derived from the database of patient information system. Analysis of biochemistry and radiological examinations, such as chest x-ray, brain magnetic resonance imaging were obtained from the medical records. Baseline cognitive status and depressive symptom were assessed before surgery day 1 using Mini-Mental State Examination (MMSE) and recorded by anesthetist in anesthetic outpatient [MMSE Score Pre-].

Intraoperative data included the operative procedure, durations of anesthesia and surgery, time from anesthesia induction to reaming femoral medullary cavity (Time A to R), doses of anesthetic agents, estimated bleeding, intraoperative blood salvage, volumes of blood products transfused, types and volumes of fluids transfusion, and use of vasoactive agents, biochemistry examinations, $\mathrm{BIS}$ values, baseline score of $\mathrm{rSctO}_{2}$ before anesthesia (pre-anesthesia), intraoperative $\mathrm{rSctO}_{2}$ score of every 15 minutes (anesthesia induction, 15 minutes post-anesthesia, 30 minutes postanesthesia, 45 minutes post-anesthesia, 60 minutes post-anesthesia, 75 minutes post-anesthesia), intra-arterial pressure measurements, nasopharyngeal temperature and urine output were noted in the anesthesia information system. $\mathrm{rSctO}_{2}$ readings of 15 minutes post-anesthesia were subtracted $\mathrm{rSctO}_{2}$ readings of 75 minutes post-anesthesia to obtain the difference $(\Delta \mathrm{X})$, then calculated the difference's average values( $\Delta \mathrm{X})$ and their standard deviations[ $\operatorname{SD}(\Delta \mathrm{X})]$.

Postoperative score of $\mathrm{SPO}_{2}$, the use of analgesics, duration in PACU $(>2 \mathrm{~h})$ were examined from the nursing record chart. The postoperative complications were also evaluated in all patients. Lab data, partial pressure of oxygen and carbon dioxide, postoperative pain, dose of analgesics at day 1 and 2 postoperatively were acquired from the medical records. Postoperative coagulation status were detected by using thromboelastogram.

\section{POD diagnosis}

Information on changes in mental status, POD diagnosis and treatment, and the psychiatrist's consult suggestion were obtained from the medical and nursing records. When patients revealed such symptoms as disorientation, memory impairment, increased or decreased psychomotor activity and perceptual disturbances, staffs in the ward according to routine consulted the psychiatrist who diagnosed whether patients suffered from POD or not based on the criteria from the Diagnostic and Statistical Manual of Mental Disorders (DSM-IV-TR table 1). 
Table 1 diagnostic and statistical manual of mental disorders (DSM-IV-TR 4th edition) diagnostic criteria for delirium

\begin{tabular}{ll}
\hline Number & Characteristic \\
\hline A & Reduced ability to maintain and shift attention to external stimuli \\
B & Disorganized thinking, as indicated by rambling, irrelevant, or incoherent speech \\
C & At least two of following: \\
& 1 Reduced level of consciousness \\
& 2 Perceptual disturbances; misinterpretations; illusion, or hallucinations \\
& 3 Disturbance of sleep-wake cycle with insomnia or daytime sleepiness \\
& 4 Increased or decreased psychomotor activity \\
& 5 Disorientation to time, place, or person \\
& 6 Memory impairment \\
D & Abrupt onset of symptoms(hours to days), with daily fluctuation \\
E & Either one of the following: \\
& 1 Evidence from history, physical examination, or laboratory tests of specific organic etiologic \\
& 2 Exclusion of non-organic mental disorders when no etiologic organic factor can be identified \\
\hline
\end{tabular}

Prognosis of delirious patient was collected from the medical and nursing records. The medical and nursing records review was continued throughout the duration of the hospitalization in this retrospective study.

\section{Statistical Analysis}

Continuous variables were analyzed using the unpaired t-test or Mann-Whitney U-test; Categorical variables were analyzed using the $\square^{2}$ test or Fisher exact test; Odds ratios (ORs) were calculated by logistic regression analysis. Data are presented as mean \pm SD. The $\square^{2}$ test for categorical variables was used in the comparison of gender, BMI grade, education class, ASA physical status, medication history and comorbidities between the delirium patients and the nodelirium patients. The t-test was used for continuing variables of the difference in the mean values such as duration time and dose and laboratory data between the two groups. The covariates with $P$-values of $<0.20$ in bivariate association with POD were included in a multivariable logistic regression model, and the forward stepwise (conditional) logistic regression was employed to identify factors independently related to the development of POD. The Hosmer-Lemeshow test was used to judge model fit. $P$-values of $<0.05$ were considered of statistically significance. SPSS 25 for Windows (SPSS Inc, Chicago, IL, USA) software was used for all statistical analyses.

\section{Results}

\section{Patients Demographic and Clinical Data}

There are 4834 aged patients who underwent right or left total hip joint replacement in our university hospital. 351 patients with an average age 74.4years (range from 65 to 87 years) were eligible for this retrospective research. Of 351 patients, 140 (39.8\%) were male and 211 (60.1\%) were female. There were 75 patients whose age was below 70 in this study. POD was found in 27 patients (fig 1), including 18 female and 9 male. Of these 27 patients, 9 patients' age was below 70; 11 patients had osteoarthrosis of hip, 10 fracture of femoral head, 2 tumor of proximal femur, and 4 necrosis of femoral head. The incidence of delirium was $7.7 \%$ in the patients $(n=351)$ and $6.5 \%$ over age $70(n=276)$. The onset was acute in all patients. The symptoms of 21 patients manifested hypoactive, 6 hyperactive; all patients were diagnosed as POD on postoperative day 1. Table 2 and Table 3 represent the patient characteristics, intraoperative and postoperative variables and bivariate associations with POD.

Table2 Preoperative/Intraoperative variables 


\begin{tabular}{|c|c|c|c|c|c|c|c|}
\hline \multirow[t]{2}{*}{ Preoperative } & Delirium & $\begin{array}{l}\text { No } \\
\text { Delirium } \\
\text { delirium }\end{array}$ & $\begin{array}{l}\mathrm{P} \\
\text { value }\end{array}$ & \multirow[t]{2}{*}{ Preoperative } & Delirium & $\begin{array}{l}\text { No } \\
\text { Delirium }\end{array}$ & \multirow[t]{2}{*}{$\begin{array}{l}\mathrm{P} \\
\text { value }\end{array}$} \\
\hline & $\mathrm{n}=27$ & $\mathrm{n}=324$ & value & & $\mathrm{n}=27$ & $\mathrm{n}=324$ & \\
\hline$\overline{\operatorname{Age}(\mathrm{y})}$ & & & 0.758 & $\mathrm{Ca}$ & $9.0 \pm 0.4$ & $9.2 \pm 0.2$ & 0.77 \\
\hline $65 \sim$ & $9(3.3 \square$ & $66(20.4)$ & & Blood sugar(mg/dl) & $111 \pm 19.9$ & $109 \pm 29.0$ & 0.59 \\
\hline $70 \sim$ & $4(14.9)$ & $97(29.9)$ & & Total protein (g/dl) & $6.6 \pm 0.5$ & $6.4 \pm 0.7$ & 0.67 \\
\hline $75 \sim$ & $6(22.2)$ & $100(30.9)$ & & $\operatorname{Albumin}(\mathrm{g} / \mathrm{dl})$ & $3.7 \pm 0.1$ & $3.8 \pm 1.0$ & 0.34 \\
\hline $80 \sim$ & $8(29.6)$ & $61(18.8)$ & & Urea nitrogen $(\mathrm{mg} / \mathrm{dl})$ & $18.2 \pm 1.8$ & $17.9 \pm 2.0$ & 0.63 \\
\hline gender & & & 0.026 & $\begin{array}{l}\text { Alanine } \\
\text { aminotransferase }(\mathrm{U} / \mathrm{L})\end{array}$ & $29 \pm 3.0$ & $31 \pm 5.1$ & 0.81 \\
\hline Female & $18(66.4)$ & 193(59.6) & & $\begin{array}{l}\text { Serum } \\
\text { bilirubin }(\mathrm{mo} / \mathrm{dl})\end{array}$ & $0.7 \pm 0.2$ & $0.9 \pm 0.3$ & 0.39 \\
\hline Male & $9(33.3)$ & $131(40.4)$ & & $\begin{array}{l}\mathrm{rSctO}_{2} \text { pre-anesthesia } \\
(\%)\end{array}$ & $67.7 \pm 6.5$ & $68.6 \pm 4.3$ & 0.25 \\
\hline \multirow{2}{*}{$\begin{array}{l}\mathrm{BMI}\left(\mathrm{kg} \cdot \mathrm{m}^{-2}\right) \\
<18.5\end{array}$} & & & 0.777 & \multirow{3}{*}{ Intraoperative } & & & \\
\hline & $8(29.7)$ & $70(21.6)$ & & & Delirium & $\begin{array}{l}\text { No } \\
\text { Delirium }\end{array}$ & \multirow[t]{2}{*}{$\begin{array}{l}\mathrm{P} \\
\text { value }\end{array}$} \\
\hline $18.5-24$ & $9(33.3)$ & $112(34.6)$ & & & $\mathrm{n}=27$ & $\mathrm{n}=324$ & \\
\hline $24-28$ & $5(18.5)$ & $89(27.5)$ & & \multirow{2}{*}{$\begin{array}{l}\text { Time [A to R] (min) } \\
\text { Duration } \\
\text { anesthesia(min) }\end{array}$} & $39.4 \pm 3.1$ & $38.4 \pm 2.9$ & 0.49 \\
\hline$>28$ & $5(18.5)$ & $53(16.3)$ & & & $92.2 \pm 9.4$ & $100.1 \pm 11.0$ & 0.54 \\
\hline \multicolumn{3}{|l|}{ Education(y) } & 0.589 & $\begin{array}{l}\text { Duration } \\
\text { surgery(min) }\end{array}$ & $59.5 \pm 11.0$ & $61.5 \pm 9.3$ & 0.72 \\
\hline$<6$ & $12(44.4)$ & $142(43.8)$ & & \\
\hline $6-12$ & $7(25.9)$ & $96(29.6)$ & & Propofol(mg) & $380 \pm 16$ & $377 \pm 10$ & 0.77 \\
\hline$>12$ & $8(29.7)$ & $86(26.6)$ & & Sufentanil $(\mu \mathrm{g})$ & $42 \pm 3.2$ & $39 \pm 2.8$ & 0.72 \\
\hline physical & & & 0.367 & Remifentanil $(\mu \mathrm{g})$ & $400 \pm 24$ & $389 \pm 17$ & 0.68 \\
\hline status & $5(18.5)$ & $73(22.5)$ & & Rocuronium(mg) & $35 \pm 4$ & $41 \pm 5$ & 0.71 \\
\hline [I & $9(33.3)$ & $112(37.6)$ & & vasoactive agents & & & 0.218 \\
\hline [II & $13(48.2)$ & $139(42.9)$ & & Phenylephrine & $7(25.9)$ & $75(23.1)$ & \\
\hline surgery & $11(40.7)$ & $140(43.2)$ & 0.944 & Ephedrine & $7(25.9)$ & $84(26.0)$ & \\
\hline history medication & & & 0.531 & Blood transfusion & $1(3.7)$ & $14(4.3)$ & 0.497 \\
\hline Anticoagulant & $6(22.2)$ & $83(25.6)$ & & Dose of hemostatic & & & \\
\hline ACE inhibitor & $4(14.8)$ & $40(12.3)$ & & Tranexamic acid & $1.5 \pm 0.5$ & $1.4 \pm 0.6$ & 0.71 \\
\hline Antidiabetic & $3(11.1)$ & $52(16.0)$ & & Dose of analgesic & & & \\
\hline Antilipemic agents & $6(22.2)$ & $57(17.6)$ & & hydromorphone & $1.5 \pm 0.5$ & $1.5 \pm 0.3$ & 0.75 \\
\hline B-receptor & $2(7.5)$ & $4(1.2)$ & & Dezocine & $4.5 \pm 1.0$ & $3.8 \pm 0.7$ & 0.77 \\
\hline $\begin{array}{l}\text { antagonist } \\
\text { Preoperative }\end{array}$ & & & 0.412 & Bleeding (ml) & $103 \pm 21$ & $110 \pm 9$ & 0.65 \\
\hline Carotid artery & $4(14.8)$ & $45(13.9)$ & & Intraoperative & & & \\
\hline Rheumatoid & $2(7.4)$ & $42(9.3)$ & & Crystalloid solution & $1000 \pm 68$ & $990 \pm 45$ & 0.59 \\
\hline $\begin{array}{l}\text { Arthritis } \\
\text { Depression/anxiety }\end{array}$ & $2(7.4)$ & 30( & & $\mathrm{He}$ & $11.7 \pm 1.1$ & $11.9 \pm$ & 0.61 \\
\hline Hypertension & $2(7.4)$ & $21(6.5)$ & & Sodium(mEq/L) & $139 \pm 4.1$ & $141 \pm 2.6$ & 0.70 \\
\hline Diabetes mellitus & $2(7.4$ & 36( & & Pot & $4.1 \pm 0.6$ & & 0.74 \\
\hline Atrial fibrillation & $4(14.8)$ & $43(13.2)$ & & Calcium(mg/dl) & $8.8 \pm 0.5$ & $9.1 \pm 0.9$ & 0.61 \\
\hline Coronary & $2(7.4)$ & $16(4.9)$ & & Blood sugar(mg/dl) & $120 \pm 12.9$ & $119 \pm 20.5$ & 0.52 \\
\hline $\begin{array}{l}\text { atherosclerosis } \\
\text { COPD }\end{array}$ & $1(3.7)$ & $15(4.6)$ & & Total protein $(\mathrm{g} / \mathrm{dl})$ & $6.3 \pm 0.2$ & $6.1 \pm 0.9$ & 0.73 \\
\hline Valvar & $5(18.6)$ & $65(17.3)$ & & Albumin $(\mathrm{g} / \mathrm{dl})$ & $4,0 \pm 0.4$ & $3.9 \pm 0.5$ & 0.57 \\
\hline $\begin{array}{l}\text { disease } \\
\text { Cardiac } \\
\text { insufficiency }\end{array}$ & $3(11.1)$ & $31(9.6)$ & & Urea & $3.9 \pm 0.5$ & $4.5 \pm 1.2$ & 0.77 \\
\hline $\begin{array}{l}\text { insufficiency } \\
\text { MMSE Score Pre- }\end{array}$ & $29.2 \pm 1.1$ & $28.9 \pm 2.0$ & 0.56 & $\begin{array}{l}\text { nitrogen }(\mathrm{mmol} / \mathrm{L}) \\
\text { Lactic acid }(\mathrm{mmol} / \mathrm{ml})\end{array}$ & $1.0 \pm 0.1$ & $0.8 \pm 0.3$ & 0.62 \\
\hline Hemoglobin (g/dl) & $12.3 \pm 1.4$ & $13.9 \pm 1.6$ & 0.67 & $\mathrm{PaCO}_{2}(\mathrm{mmHg})$ & $39 \pm 3.0$ & $40 \pm 2.3$ & 0.73 \\
\hline $\mathrm{PaO}_{2}(\mathrm{mmHg})$ & $69 \pm 2.5$ & $68 \pm 1.3$ & 0.59 & Base excess $(\mathrm{mmol} / \mathrm{L})$ & $0.2 \pm 0.5$ & $0.0 \pm 0.7$ & 0.71 \\
\hline Sodium(mEq/L) & $141 \pm 4.9$ & $141 \pm 3.7$ & 0.76 & $\operatorname{Mean}(\Delta \mathrm{X}) \pm \operatorname{SD}(\Delta \mathrm{X})$ & $12.4 \pm 4.1$ & $2.9 \pm 3.2$ & 0.000 \\
\hline Potassium( $\mathrm{mEq}$ & $4.0 \pm 0.3$ & $4.1 \pm 0.4$ & 0.74 & Duration in & $3(11.1)$ & $13(4.0)$ & 0.232 \\
\hline
\end{tabular}

Page 6/16 
Data are presented as mean $( \pm \mathrm{SD})$ or median (interquartile range) or number of patients $(\%)$. BMI=body mass index; $\mathrm{ASA}=$ American Society of Anesthesiologists; $\mathrm{ACE}=$ angiotensin converting enzyme; COPD = chronic obstructive pulmonary disease; Cardiac insufficiency, ejection fraction<30\%; MMSE Score Pre-, MiniMental state Examination before surgery day $1 ; \mathrm{rSctO}_{2}$ pre-anesthesia, $\mathrm{rSctO}_{2}$ reading before anesthesia; Time [A to R], time from anesthesia induction to reaming femoral medullary cavity; $\Delta \mathrm{X}=$ difference of $\mathrm{rSctO}_{2}$ readings in 15 minutes post-anesthesia versus in 75 minutes post-anesthesia.

Table 3 Postoperative variables. Data are presented as mean $( \pm \mathrm{SD})$ or number of patient $(\%)$.

\begin{tabular}{|c|c|c|c|}
\hline & $\begin{array}{l}\text { Delirium } \\
\mathrm{n}=27\end{array}$ & $\begin{array}{l}\text { No delirium } \\
\mathrm{n}=324\end{array}$ & $\mathrm{P}$ value \\
\hline \multicolumn{4}{|l|}{1 day after operation } \\
\hline $\operatorname{Hemoglobin}(\mathrm{g} / \mathrm{L})$ & $10.1 \pm 0.6$ & $10.5 \pm 1.1$ & 0.38 \\
\hline Sodium(mEq/L) & $136 \pm 3.9$ & $139 \pm 4.0$ & 0.67 \\
\hline $\operatorname{Potassium}(\mathrm{mEq} / \mathrm{L})$ & $4.0 \pm 0.4$ & $4.1 \pm 0.2$ & 0.62 \\
\hline Calcium(mg/dl) & $8.7 \pm 0.9$ & $8.5 \pm 0.5$ & 0.54 \\
\hline Total protein $(\mathrm{g} / \mathrm{dl})$ & $5.5 \pm 0.5$ & $5.3 \pm 0.2$ & 0.29 \\
\hline $\operatorname{Albumin}(\mathrm{g} / \mathrm{dl})$ & $3.0 \pm 0.5$ & $3.1 \pm 0.2$ & 0.40 \\
\hline Urea nitrogen (mmol/L) & $4.1 \pm 0.3$ & $4.5 \pm 1.1$ & 0.74 \\
\hline Alanine aminotransferase(U/L) & $28 \pm 0.3$ & $30 \pm 0.6$ & 0.65 \\
\hline Base excess (mmol/L) & $0.7 \pm 0.3$ & $0.8 \pm 0.3$ & 0.73 \\
\hline $\mathrm{PaO}_{2}(\mathrm{mmHg})$ & $89 \pm 4.0$ & $91 \pm 6.3$ & 0.47 \\
\hline $\mathrm{PaCO}_{2}(\mathrm{mmHg})$ & $39 \pm 3.6$ & $40 \pm 4.4$ & 0.49 \\
\hline analgesics & & & 0.641 \\
\hline Dezocine & $4(14.8)$ & $43(13.3)$ & \\
\hline Flurbiprofen axetil (mg) & $5(18.5)$ & $55(17.0)$ & \\
\hline morphine & $3(11.1)$ & $43(13.3)$ & \\
\hline hydromorphone & $2(7.4)$ & $15(4.6)$ & \\
\hline \multicolumn{4}{|l|}{2 day after operation } \\
\hline $\operatorname{Hemoglobin}(\mathrm{g} / \mathrm{dl})$ & $10.2 \pm 0.4$ & $10.0 \pm 1.0$ & 0.32 \\
\hline $\operatorname{Sodium}(\mathrm{mEq} / \mathrm{L})$ & $130 \pm 2.5$ & $135 \pm 1.1$ & 0.71 \\
\hline $\operatorname{Potassium}(\mathrm{mEq} / \mathrm{L})$ & $3.6 \pm 0.2$ & $3.9 \pm 0.5$ & 0.54 \\
\hline Calcium(mg/dl) & $8.5 \pm 0.7$ & $8.5 \pm 0.2$ & 0.73 \\
\hline Total protein $(\mathrm{g} / \mathrm{dl})$ & $5.1 \pm 0.7$ & $5.6 \pm 0.6$ & 0.53 \\
\hline $\operatorname{Albumin}(\mathrm{g} / \mathrm{dl})$ & $3.1 \pm 0.3$ & $3.3 \pm 0.5$ & 0.51 \\
\hline Urea nitrogen (mmol/L) & $4.5 \pm 0.5$ & $4.4 \pm 0.9$ & 0.61 \\
\hline Alanine aminotransferase(U/L) & $28 \pm 0.6$ & $31 \pm 0.9$ & 0.62 \\
\hline Base excess $(\mathrm{mmol} / \mathrm{L})$ & $1.0 \pm 0.3$ & $0.9 \pm 0.1$ & 0.77 \\
\hline $\mathrm{PaO}_{2}(\mathrm{mmHg})$ & $91 \pm 5.0$ & $90 \pm 5.2$ & 0.48 \\
\hline $\mathrm{PaCO}_{2}(\mathrm{mmHg})$ & $39 \pm 3.0$ & $40 \pm 2.3$ & 0.43 \\
\hline
\end{tabular}

27 patients found to be delirious after surgery (Delirium $n=27), 324$ patients who did not develop delirium after surgery serves as the no-delirium group (No Delirium n=324). Preoperative patient characteristics such as age, $\mathrm{BMI}$, education grade, ASA physical status and MMSE Scores Pre- were no significant difference between Delirium group and No Delirium group $(p>0.05)$. It was noted that there was no statistical difference in the past medical history and surgical history as well as comorbidities between two groups ( $p$ value $>0.05)$. There was no difference in preoperative Hemoglobin mean value of 12.3 \pm 1.4 (Delirium group) compared with $13.9 \pm 1.6$ (No Delirium group) $(p=0.67)$. As to intraoperative area, there were no statistical difference in the data of the average operation time, blood loss, dose of anesthetic, the amount of infusion, and Lab tests between the two groups. Use of analgesic and partial pressure of carbon dioxide did not differ significantly between Delirium group and No Delirium group. Although there are 3 cases in 
Delirium group and 13 cases in No Delirium group whose duration of stay in Postoperative Care Unit over 2 hours referring to discharge standard of PACU, the results did not reach statistical significance $(p=0.232)$.

In postoperative data, laboratory data at day 1 and day 2 after surgery such as hemoglobin, hematocrit, total protein, albumin, sodium, potassium, calcium, blood sugar, serum urea nitrogen, partial pressure of oxygen as well as partial pressure of carbon dioxide were not different in statistics between the two groups $(p>0.05)$. The use of analgesic at day 1 after surgery were no significantly difference in Delirium group, compared with those in No Delirium group $(p=0.64)$. All patients at day 2 after surgery didn't use any analgesic because visual analogue scale was below 3 (table 3 ).

Generally, the symptoms of delirium subsided 4-5 days after surgery. We followed up all of delirium patients for 30 days by consulting the follow-up message system in our hospital. 24 patients recovered. One patient had persistent and severe cognitive dysfunction after surgery, two patients died of complications either acute pulmonary embolism 4 days after surgery or acute stroke 21 days after surgery respectively.

\section{rSct02 Change}

rSct02 reading of pre-anesthesia were $68.8 \pm 6.2$ and $69.2 \pm 4.6$ respectively between two groups, there were no statistical significance $(p=0.34)$. $\mathrm{rSctO}_{2}$ scores were not found a statistical difference in the pre-anesthesia and anesthesia induction as well as 15 minutes post-anesthesia between two groups $(p>0.05)$. It was noteworthy that there was significantly different in mean value of $\mathrm{rSctO}_{2}$ of 45 minutes post-anesthesia between two groups $(p=0.00)$ (Fig 2), so was $\mathrm{rSctO}_{2}$ of 60 minutes post-anesthesia or $\mathrm{rSctO}_{2}$ of 75 minutes post-anesthesia respectively between two groups. In Delirium group, mean value of $\mathrm{rSctO}_{2}$ of 45 minutes post-anesthesia was $82 \%$ of mean value of $\mathrm{rSctO}_{2}$ of 15 minutes post-anesthesia ( $p=0.000,68.42 \pm 5.90$ compared $56.03 \pm 6.32$ ), though there was also a bit drop in No Delirium group ( $p=$ $0.125,69.20 \pm 4.52$ compared $66.27 \pm 4.92)$.

\section{Logistic Regression Analysis}

There was some difference in variable gender $(p=0.026)$. Besides Gender, variables in Table 2 (age, BMI, education level, ASA physical status, preoperative comorbidities, past surgery history, past medication history, vasoactive agents, blood transfusion, Duration in PACU $(>2 \mathrm{~h})$, mean value of difference $\mathrm{rSctO}_{2}(\Delta \mathrm{X})$ ) and Table 3 (analgesics) were added to the multivariable logistic analysis. The final model was determined by the forward selection method with introduce criterion having significance level of 0.05 (table 4). Final model included two variables: gender $(p=0.026)$, mean value of difference $\mathrm{SctO}_{2}(\Delta \mathrm{X})(p=0.000)$. The Hosmer-Lemeshow test appeared a good fit $\left(\square^{2}=11.909, p=0.155\right)$.

Table 4 Multi-variables Logistic regression analysis: independent factors causing postoperative delirium.

\begin{tabular}{|c|c|c|}
\hline Factor & OR $(95 \% \mathrm{CI})$ & $P$ Value \\
\hline Age & $1.127[0.5282 .402]$ & .758 \\
\hline Gender & $0.105[0.0140 .760]$ & .026 \\
\hline BMI grade & $1.127[0.4942 .570]$ & .777 \\
\hline Education class & $0.788\left[\begin{array}{lll}0.331 & 1.873\end{array}\right]$ & .589 \\
\hline ASA physical status & $1.634[0.5624 .750]$ & .367 \\
\hline Surgery history & $0.949[0.2204 .100]$ & .944 \\
\hline Medications history & $1.156\left[\begin{array}{lll}0.734 & 1.823\end{array}\right]$ & .531 \\
\hline Comorbidity before surgery & $0.896\left[\begin{array}{lll}0.689 & 1.165\end{array}\right]$ & .412 \\
\hline Vasoactive agents during surgery & $1.787[0.7094 .506]$ & .218 \\
\hline Blood infusion during surgery & $0.599[0.1372 .629$ & .497 \\
\hline Analgesics 1 day post-operation & $1.148[0.6432 .050$ & .641 \\
\hline Duration of PACU & $4.954[0.35968 .309]$ & .232 \\
\hline Difference of $\mathrm{rSctO}_{2}$ readings & $980]$ & .000 \\
\hline
\end{tabular}

OR: odds ratio; 95\% CI: 95\% confidence interval. Difference of $\mathrm{rSctO}_{2}$ readings: difference of $\mathrm{rSctO}_{2}$ readings in 15 minutes post-anesthesia versus in 75 minutes post-anesthesia 


\section{Discussion}

This study focused on investigating the risk factors and the morbidity of POD after hip arthroplasty in the elder. We found that 27 patients who had hip replacement in past 4 years developed POD, although this was a retrospective analysis.

Previous reports studied perioperative delirium in older patients. Zywiel [29] stated that its incidence was up to 50-70\% of high-risk patients groups, although only $2-3 \%$ in the general surgical populations. Recently, however, Scott [30] reported the incidence of postoperative delirium on total joint replacement patients was $17 \%$. Variety of incidence in POD depended upon type of surgery and preoperative physical condition as well as a variety of stress, such as pain, immobilization, and psychological stress. This cohort study demonstrated that the incidence of POD was 7.7\%, this is not in line with previous reported literature [1,29]. We assayed possible reasons for declining in Incidence of POD. Firstly, we improved the preoperative physical condition before surgery and patient care such as fast track program/ geriatric sunset glow program. Tammy and colleague [31] regarded the preoperative physical condition as a predicting factor for POD, so improvement of the physical condition before surgery might be important for preventing POD. Our patients improved internal environment disorders and guided physical training before surgery. Although early transfusion strategy to maintain hematocrit at $>30 \%$ should be one component of a multifactorial intervention strategy to prevent delirium, several observational studies [32,33] found that intraoperative allogenic blood transfusion is an independent risk factor for POD, and there is a dose-dependent relationship between volume transfused and the risk of POD. Few patients transfused allogenic blood products in this study. Geriatric sunset glow program or fast track approach, avoiding prolonged ( $>6 \mathrm{~h}$ ) fluid fasting, reducing dehydration and unnecessary use of i.v. fluids have been put into practice for several years in our hospital. Radtke [34] confirmed that fluid fasting for over $6 \mathrm{~h}$ is an independent risk factor for developing POD. Secondly, BIS value between 40 and 60, depth of anesthesia monitoring, avoided excessively deep anesthesia. Bocskai T and colleague [35] stated that depth of anesthesia monitoring is associated with a significantly lower risk of POD. Thirdly, normal partial pressure of carbon dioxide and maintaining arterial pressure above $90 \%$ of baseline value protected against low cerebral perfusion pressure. Most notably, high cerebral perfusion pressure was harmful. A retrospective research [36] indicated cerebral perfusion pressure over the auto-regulatory limit is an independent risk factor for the development of POD. Fourthly, perfect use of multimodal analgesia reduced pain stress response after surgery. Weinstein [37] pointed out that use of regional anesthesia is independently associated with a 20$40 \%$ lower incidence of delirium. Fifthly, encouragement early getting out of bed and functional training after surgery could improve psychological activities. Sixthly, we excluded one delirious patient because of allergic shock during surgery. Increased vasopressor requirement representing a greater degree of cardiovascular compromise, several observational studies $[38,39]$ have indicated that POD is related to higher intraoperative vasopressor requirement. We also screened two patients who inhaled volatile anesthetic. Some experimental studies [40] showed that volatile anesthetics may be induce cell injury and even promote neuro-pathogenesis, so volatile anesthetics were regarded as high risk factor for POD. On the contrary, others researches [41] demonstrated that volatile anesthetics take neuroprotective effect and do not provide any convincing data to verify their impact on POD. Dexmedetomidine [42] increases the duration of sleep and the duration of deeper sleep. However, sleep disturbance is commonly associated with delirium, so we still shield one patient who was administrated dexmedetomidine intraoperatively.

At present, the risk factors for POD is thought to be multifactorial. Referring to previous literature [4-23] , we found that following factors are independent high-risk factors for the development of POD: type of surgical procedures, major emergency surgery, age, ASA grade, pain, postoperative intensive care admission, prolonged fluid fasting, anemia, general anesthesia, benzodiazepines, depression/anxiety, and medical comorbidity, education and preoperative functional status. This study revealed that gender was high risk factor for POD, this was consistent with previous literature $[5,6,43]$. We did not found that age and education grade were associated with this increased risk. As for mental factors [20] such as

Page 9/16 
depression/anxiety might be related to the occurrence of POD. But it is worth noting that mental factors were not found to play an important role in inducing POD in this cohort study. These results were different from previous reports by other authors $[4,8,20]$. Further studies should be carried out to research the relationship between the POD and these factors in detail, this will be our next study issue.

POD usually develops with a fluctuating course and spontaneously recovers to normal within a few weeks after surgery. However, some studies [44] have showed that delirium is a less transient disorder than was previous believed. Recent research [45]have confirmed that delirium is a common complication in elderly patients, and is associated with a longer and more complicated hospital stay and increased short and long-term mortality. High mortality and morbidity as well as higher healthcare cost have drawn widespread attention, researchers have put a lot of efforts into studying. In terms of the pathophysiological mechanism, there are three doctrines based on evidence almost from animal models rather than from human in vivo. Neuro-inflammation theory [26] considered that cerebral inflammatory mediators result in the loss of synaptic plasticity, neuro-apoptosis, and impaired neurogenesis, which are associated with higher risks of POD.

Neurotransmitters hypothesis [28] deemed that lower postoperative acetylcholinesterase activity was an independent risk factor for developing POD. The third view took for that subclinical cerebral vascular events [32] contributed to developing POD. So far, the exact mechanism of POD was still unknown, it is widely believed that delirium is thought to represent not only cerebral dysfunction but also an impaired general physical condition. In addition, treatment options of management for established POD is very limited, and what's more, treatment do not either change the time course of delirium or modify prognosis. That is to say, current treatment measures do not appear to reduce the risk of mortality and morbidity for POD, although recent research has been put persistent effort into revealing more regarding its pathogenesis. So, up to now, more effective management in terms of POD is reducing the perioperative risk [46] (including improvement of the preoperative physical condition). Besides, it is indispensable for an effective and a real-time intraoperative monitoring so as to take measures to ensure normal cerebral perfusion and oxygen supply, including BIS-guided anesthesia, hematocrit $>30 \%$, arterial pressure $>90 \%$ of baseline value and $\mathrm{rSctO}_{2}$ monitoring. Several studies $[47,48]$ reported that cerebral hypo-perfusion is associated with POD. Regional cerebral hypo-perfusion in a real-time manner indicate low reading of $\mathrm{rSctO}_{2}$. Regional cerebral perfusion depends on several factors in a way involving fraction of inspired oxygen, hemoglobin concentration, mean arterial pressure and cerebral blood flow. Regional cerebral blood flow was bound to decrease once subclinical cerebral vascular events occurred, resulting in regional cerebral hypo-perfusion and low reading of $\mathrm{rSctO}_{2}$ and even postoperative cognitive dysfunction because of neuronal injury. Most notably, this study revealed that the decrease in $\mathrm{rSctO}_{2}$ readings intraoperatively related to $\mathrm{POD}$. The result is consistent with the reported literature. Tomaszewski D [49] confirmed that the decrease in $\mathrm{rSctO}_{2}$ readings may be due to micro-thromboembolic events in patients after total hip arthroplasty and S100B may be a more specific marker of astroglial damage. Tyler Ballweg [50] reported that the change in perioperative neuronal injury biomarker tau was associated with delirium incidence and severity. We observed the relation between surgery procedure and $\mathrm{rScto}_{2}$ score in different time point. After reaming femoral medullary cavity (mean time 39 minutes, from anesthesia induction to reaming medullary cavity), $\mathrm{rScto}_{2}$ reading of at 15 minutes post-anesthesia in Delirium group was sharply dropped to mean 56 at 45 minutes postanesthesia. These patients developed POD. All delirious patients scanned brain by diffusion-weighted magnetic resonance imaging day 1 or day 2 after surgery, new micro-embolic brain lesion were found. We consider that the decrease in $\mathrm{rSctO}_{2}$ readings indicated regional cerebral hypo-perfusion due to cerebral micro-embolus which caused POD.

There are some limits in this study. At first, we assessed POD on the first two postoperative days, therefore delirium that occurred in later postoperative days would have been missed. However, the incidence of POD is higher in the first several days after surgery, and we deemed that we have captured results from the most important time period. We paid great attention to the hypoactive type, much more common than the hyperactive delirium, day 1 or day 2 after surgery. Hypoactive delirium is usually neglected or misdiagnosed as depression because of lack of routine screening for symptoms of hypoactive delirium. Secondly, our studies focused on patients who underwent elective hip replacement

Page $10 / 16$ 
and the results are derived from a single institution, so it may not allow for generalizability to a broader surgical population, and the larger sample size in each group (Delirium vs No Delirium) is needed due to the relatively low incidence of this event. Additionally, future studies should consider incorporating multicenter data to research a more representative cohort. Thirdly, the use of any monitoring modality can result in false positives. Therefore it is important to verify that the electrodes are well positioned and that there is no leakage of light as a consequence of peeling of the adhesive patch. Still, bias of rScO2 exists inter-individually, likely because of differences in skin color and gender and in the volume percentage of arterial and venous blood in the monitored brain region.

In conclusion, the intraoperative decrease in $\mathrm{rSctO}_{2}$ readings was associated with POD. Unmodifiable factors, such as gender, clearly pose a significant risk for POD, and the incidence can be reduced through improvement of the physical condition before surgery and intraoperative delicacy management based on real-time monitoring. Generalizing these findings, further study will be taken into account polycentric cooperation and the larger sample size.

\section{Declarations}

Contributors: Guo-Jun Zhou and Shao-Hua Yu were responsible for conception/design of the study. Zhu-Li Wang and Rong-Xin He were responsible for data of acquisition/analysis. All authors were involved in data of interpretation. GuoJun Zhou and Rong-Xin He were involved in drafting the manuscript, and all authors repeatedly revised it for important intellectual content.

Conflicts of interest: None declared.

Source of Funding: None declared

\section{References}

1. Williams-Russo P, Urquhart B L, Sharrock N E, Charlson M E. Post-operative delirium: predictors and prognosis in elderly orthopedic patients. J Am Geriatr Soc. 1992; 40: 759-67.

2. Dyer C B, Ashton C M, Teasdale T A. Postoperative delirium. A review of 80 primary data-collection studies. Arch Intern Med. 1995; 155: 461-5.

3. Schenning K J, Deiner S G. Postoperative Delirium in the Geriatric Patient. Anesthesiol Clin. 2015; 33: 505-16.

4. Morino T, Hino M, Yamaoka S, Misaki H, Ogata T, Imai H, Miura H. Risk Factors for Delirium after Spine Surgery: An Age-Matched Analysis. Asian Spine J. 2018; 12: 703-09.

5. Uvnas-Wallenstein K, Palmblad J. Effect of food deprivation (fasting) on plasma gastrin levels in man. Scand J Gastroenterol. 1980; 15: 187-91.

6. Shi C, Yang C, Gao R, Yuan W. Risk Factors for Delirium After Spinal Surgery: A Meta-Analysis. World Neurosurg. 2015; 84: 1466-72.

7. Al Tmimi L, Van Hemelrijck J, Van de Velde M, Sergeant P, Meyns B, Missant C, Jochmans I, Poesen K, Coburn $M$, Rex S. Xenon anaesthesia for patients undergoing off-pump coronary artery bypass graft surgery: a prospective randomized controlled pilot trial. Br J Anaesth. 2015; 115: 550-9.

8. Wang L H, Xu D J, Wei X J, Chang H T, Xu G H. Electrolyte disorders and aging: risk factors for delirium in patients undergoing orthopedic surgeries. BMC Psychiatry. 2016; 16: 418. 
9. Tully P J, Baker R A, Winefield H R, Turnbull D A. Depression, anxiety disorders and Type D personality as risk factors for delirium after cardiac surgery. Aust N Z J Psychiatry. 2010; 44: 1005-11.

10. Riley C, Andrzejowski J. Inadvertent perioperative hypothermia. BJA Educ. 2018; 18: 227-33.

11. Wang C M, Huang H W, Wang Y M, He X, Sun X M, Zhou Y M, Zhang G B, Gu H Q, Zhou J X. Incidence and risk factors of postoperative delirium in patients admitted to the ICU after elective intracranial surgery: A prospective cohort study. Eur J Anaesthesiol. 2020; 37: 14-24.

12. Li H, Li C D, Yi X D, Liu H, Liu X Y. [Analysis of risk factors for delirium in the elderly patients after spinal operation]. Beijing Da Xue Xue Bao Yi Xue Ban. 2012; 44: 847-50.

13. Zhu C, Wang B, Yin J, Xue Q, Gao S, Xing L, Wang H, Liu W, Liu X. Risk factors for postoperative delirium after spinal surgery: a systematic review and meta-analysis. Aging Clin Exp Res. 2020; 32: 1417-34.

14. Thompson C, Brienza V J M, Sandre A, Caine S, Borgundvaag B, McLeod S. Risk factors associated with acute in-hospital delirium for patients diagnosed with a hip fracture in the emergency department. CJEM. 2018; 20: 911-19.

15. Cukierman T, Gerstein H C, Williamson J D. Cognitive decline and dementia in diabetes-systematic overview of prospective observational studies. Diabetologia. 2005; 48: 2460-9.

16. Wang H, Anthony D, Selemidis S, Vlahos R, Bozinovski S. Resolving Viral-Induced Secondary Bacterial Infection in COPD: A Concise Review. Front Immunol. 2018; 9: 2345.

17. Kim H, Chung S, Joo Y H, Lee J S. The major risk factors for delirium in a clinical setting. Neuropsychiatr Dis Treat. 2016; 12: 1787-93.

18. Kotfis K, Slozowska J, Listewnik M, Szylinska A, Rotter I. The Impact of Acute Kidney Injury in the Perioperative Period on the Incidence of Postoperative Delirium in Patients Undergoing Coronary Artery Bypass Grafting-Observational Cohort Study. Int J Environ Res Public Health. 2020; 17:

19. Heirene R, John B, Roderique-Davies G. Identification and Evaluation of Neuropsychological Tools Used in the Assessment of Alcohol-Related Cognitive Impairment: A Systematic Review. Front Psychol. 2018; 9: 2618.

20. Nelson S, Rustad J K, Catalano G, Stern T A, Kozel F A. Depressive Symptoms Before, During, and After Delirium: A Literature Review. Psychosomatics. 2016; 57: 131-41.

21. Kalvas L B, Monroe T B. Structural Brain Changes in Delirium: An Integrative Review. Biol Res Nurs. 2019; 21: 355-65.

22. Kawaguchi Y, Kanamori M, Ishihara H, Abe Y, Nobukiyo M, Sigeta T, Hori T, Kimura T. Postoperative delirium in spine surgery. Spine J. 2006; 6: 164-9.

23. Dujovny M, Misra M, Widman R. Cerebral oximetry-techniques. Neurol Res. 1998; 20 Suppl 1: S5-12.

24. Ikeda K, MacLeod D B, Grocott H P, Moretti E W, Ames W, Vacchiano C. The accuracy of a near-infrared spectroscopy cerebral oximetry device and its potential value for estimating jugular venous oxygen saturation. Anesth Analg. 2014; 119: 1381-92.

25. Yu B, Peng Y, Qiao H, Liu B, Wang M, Yang X, Han R. The Application of Regional Cerebral Oxygenation Monitoring in the Prediction of Cerebral Hypoperfusion During Carotid Endarterectomy. J Neurosurg Anesthesiol. 2020;

Page $12 / 16$ 
26. Liu X, Yu Y, Zhu S. Correction: Inflammatory markers in postoperative delirium (POD) and cognitive dysfunction (POCD): A meta-analysis of observational studies. PLoS One. 2018; 13: e0209284.

27. Mrkobrada M, Hill M D, Chan M T, Sigamani A, Cowan D, Kurz A, Sessler D I, Jacka M, Graham M, Dasgupta M, Dunlop V, Emery D J, Gulka I, Guyatt G, Heels-Ansdell D, Murkin J, Pettit S, Sahlas D J, Sharma M, Sharma M, Srinathan S, St John P, Tsai S, Gelb A W, O'Donnell M, Siu D, Chiu P W, Sharath V, George A, Devereaux P J. Covert stroke after noncardiac surgery: a prospective cohort study. Br J Anaesth. 2016; 117: 191-7.

28. Adam E H, Haas V, Lindau S, Zacharowski K, Scheller B. Cholinesterase alterations in delirium after cardiosurgery: a German monocentric prospective study. BMJ Open. 2020; 10: e031212.

29. Zywiel M G, Hurley R T, Perruccio A V, Hancock-Howard R L, Coyte P C, Rampersaud Y R. Health economic implications of perioperative delirium in older patients after surgery for a fragility hip fracture. $J$ Bone Joint Surg Am. 2015; 97: 829-36.

30. Scott J E, Mathias J L, Kneebone A C. Incidence of delirium following total joint replacement in older adults: a meta-analysis. Gen Hosp Psychiatry. 2015; 37: 223-9.

31. Hshieh T T, Yue J, Oh E, Puelle M, Dowal S, Travison T, Inouye S K. Effectiveness of multicomponent nonpharmacological delirium interventions: a meta-analysis. JAMA Intern Med. 2015; 175: 512-20.

32. Guo Y, Jia P, Zhang J, Wang X, Jiang H, Jiang W. Prevalence and risk factors of postoperative delirium in elderly hip fracture patients. J Int Med Res. 2016; 44: 317-27.

33. Li H C, Chen Y S, Chiu M J, Fu M C, Huang G H, Chen C C. Delirium, subsyndromal delirium, and cognitive changes in individuals undergoing elective coronary artery bypass graft surgery. J Cardiovasc Nurs. 2015; 30: 340-5.

34. Radtke F M, Franck M, MacGuill M, Seeling M, Lutz A, Westhoff S, Neumann U, Wernecke K D, Spies C D. Duration of fluid fasting and choice of analgesic are modifiable factors for early postoperative delirium. Eur $J$ Anaesthesiol. 2010; 27: 411-6.

35. Bocskai T, Kovacs M, Szakacs Z, Gede N, Hegyi P, Varga G, Pap I, Toth I, Revesz P, Szanyi I, Nemeth A, Gerlinger I, Karadi K, Lujber L. Is the bispectral index monitoring protective against postoperative cognitive decline? A systematic review with meta-analysis. PLoS One. 2020; 15: e0229018.

36. Hori D, Brown C, Ono M, Rappold T, Sieber F, Gottschalk A, Neufeld K J, Gottesman R, Adachi H, Hogue C W. Arterial pressure above the upper cerebral autoregulation limit during cardiopulmonary bypass is associated with postoperative delirium. Br J Anaesth. 2014; 113: 1009-17.

37. Weinstein S M, Poultsides L, Baaklini L R, Morwald E E, Cozowicz C, Saleh J N, Arrington M B, Poeran J, Zubizarreta N, Memtsoudis S G. Postoperative delirium in total knee and hip arthroplasty patients: a study of perioperative modifiable risk factors. Br J Anaesth. 2018; 120: 999-1008.

38. Neerland B E, Krogseth M, Juliebo V, Hylen Ranhoff A, Engedal K, Frihagen F, Raeder J, Bruun Wyller T, Watne L 0 . Perioperative hemodynamics and risk for delirium and new onset dementia in hip fracture patients; A prospective followup study. PLoS One. 2017; 12: e0180641.

39. Rudiger A, Begdeda H, Babic D, Kruger B, Seifert B, Schubert M, Spahn D R, Bettex D. Intra-operative events during cardiac surgery are risk factors for the development of delirium in the ICU. Crit Care. 2016; 20: 264. 
40. Kinjo S, Lim E, Magsaysay M V, Sands L P, Leung J M, Perioperative Medicine Research G. Volatile anaesthetics and postoperative delirium in older surgical patients-A secondary analysis of prospective cohort studies. Acta Anaesthesiol Scand. 2019; 63: 18-26.

41. Matchett G A, Allard M W, Martin R D, Zhang J H. Neuroprotective effect of volatile anesthetic agents: molecular mechanisms. Neurol Res. 2009; 31: 128-34.

42. Wu X H, Cui F, Zhang C, Meng Z T, Wang D X, Ma J, Wang G F, Zhu S N, Ma D. Low-dose Dexmedetomidine Improves Sleep Quality Pattern in Elderly Patients after Noncardiac Surgery in the Intensive Care Unit: A Pilot Randomized Controlled Trial. Anesthesiology. 2016; 125: 979-91.

43. Wu X, Sun W, Tan M. Incidence and Risk Factors for Postoperative Delirium in Patients Undergoing Spine Surgery: A Systematic Review and Meta-Analysis. Biomed Res Int. 2019; 2019: 2139834.

44. O'Keeffe S, Lavan J. The prognostic significance of delirium in older hospital patients. J Am Geriatr Soc. 1997; 45: 174-8.

45. Falsini G, Grotti S, Porto I, Toccafondi G, Fraticelli A, Angioli P, Ducci K, Liistro F, Pieroni M, Taddei T, Romanelli S, Rossi R, Bolognese L. Long-term prognostic value of delirium in elderly patients with acute cardiac diseases admitted to two cardiac intensive care units: a prospective study (DELIRIUM CORDIS). Eur Heart J Acute Cardiovasc Care. 2018; 7: 661-70.

46. Aldecoa C, Bettelli G, Bilotta F, Sanders R D, Audisio R, Borozdina A, Cherubini A, Jones C, Kehlet H, MacLullich A, Radtke F, Riese F, Slooter A J, Veyckemans F, Kramer S, Neuner B, Weiss B, Spies C D. European Society of Anaesthesiology evidence-based and consensus-based guideline on postoperative delirium. Eur J Anaesthesiol. 2017; 34: 192-214.

47. Smith P J, Blumenthal J A, Hoffman B M, Rivelli S K, Palmer S M, Davis R D, Mathew J P. Reduced Cerebral Perfusion Pressure during Lung Transplant Surgery Is Associated with Risk, Duration, and Severity of Postoperative Delirium. Ann Am Thorac Soc. 2016; 13: 180-7.

48. Maheshwari K, Ahuja S, Khanna A K, Mao G, Perez-Protto S, Farag E, Turan A, Kurz A, Sessler D I. Association Between Perioperative Hypotension and Delirium in Postoperative Critically III Patients: A Retrospective Cohort Analysis. Anesth Analg. 2020; 130: 636-43.

49. Tomaszewski D, Balkota M, Rybicki Z. Regional Cerebral Oxygen Saturation Decreases During Primary Hip Arthroplasty: An Analysis of Perioperative Regional Cerebral Oxygenation (rSO2), S100 Calcium-Binding Protein B (S100B) and Glial Fibrillary Acidic Protein (GFAP) Values. A Pilot Study. Med Sci Monit. 2019; 25: 525-31.

50. Ballweg T, White M, Parker M, Casey C, Bo A, Farahbakhsh Z, Kayser A, Blair A, Lindroth H, Pearce R A, Blennow K, Zetterberg H, Lennertz R, Sanders R D. Association between plasma tau and postoperative delirium incidence and severity: a prospective observational study. Br J Anaesth. 2021; 126: 458-66.

\section{Figures}




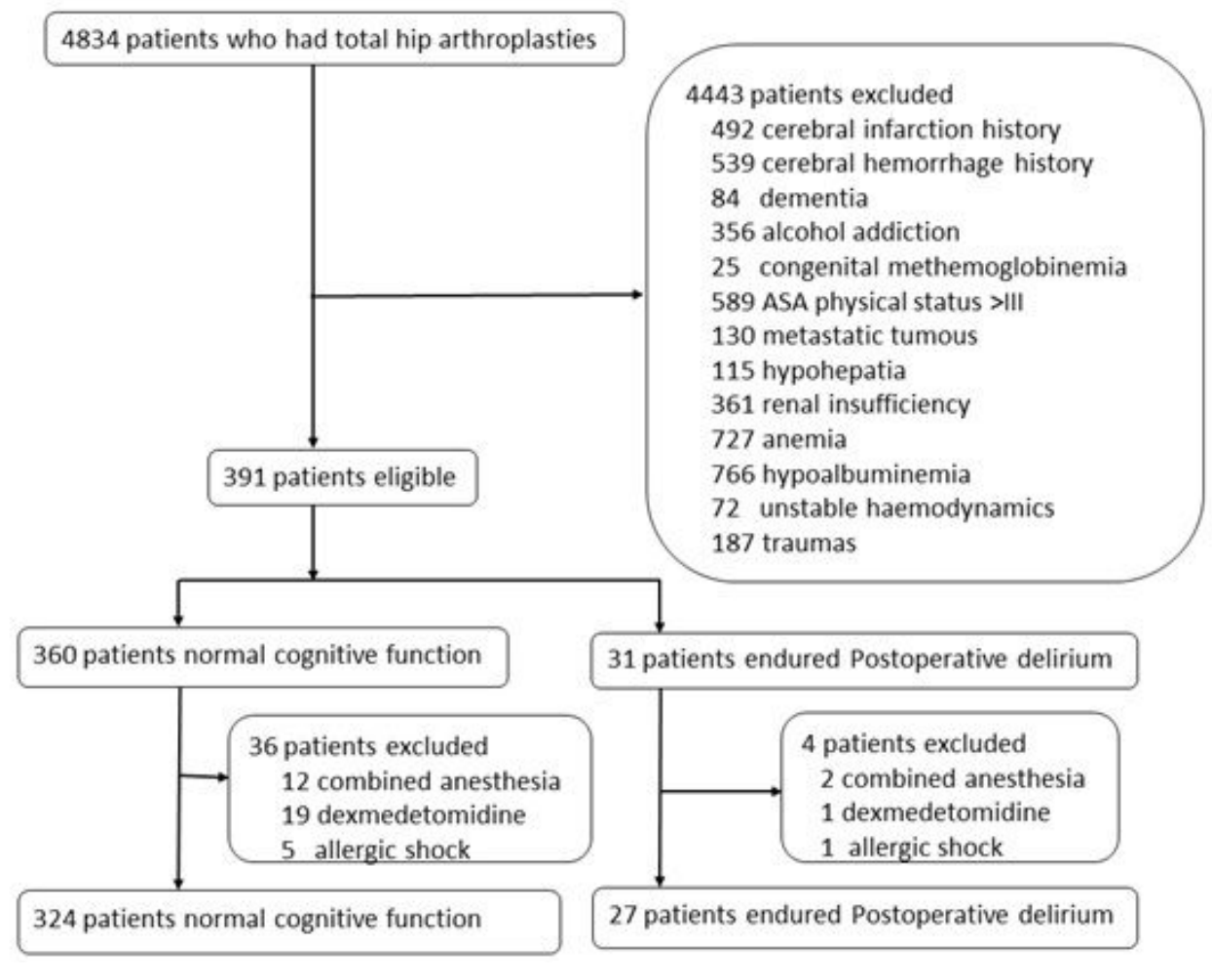

Figure 1

Patients flow chart. ASA: American Society of Anesthesiologists; Combined anesthesia: intravenous inhalational anesthesia; Unstable hemodynamics: maintaining artery pressure by pumping norepinephrine. 


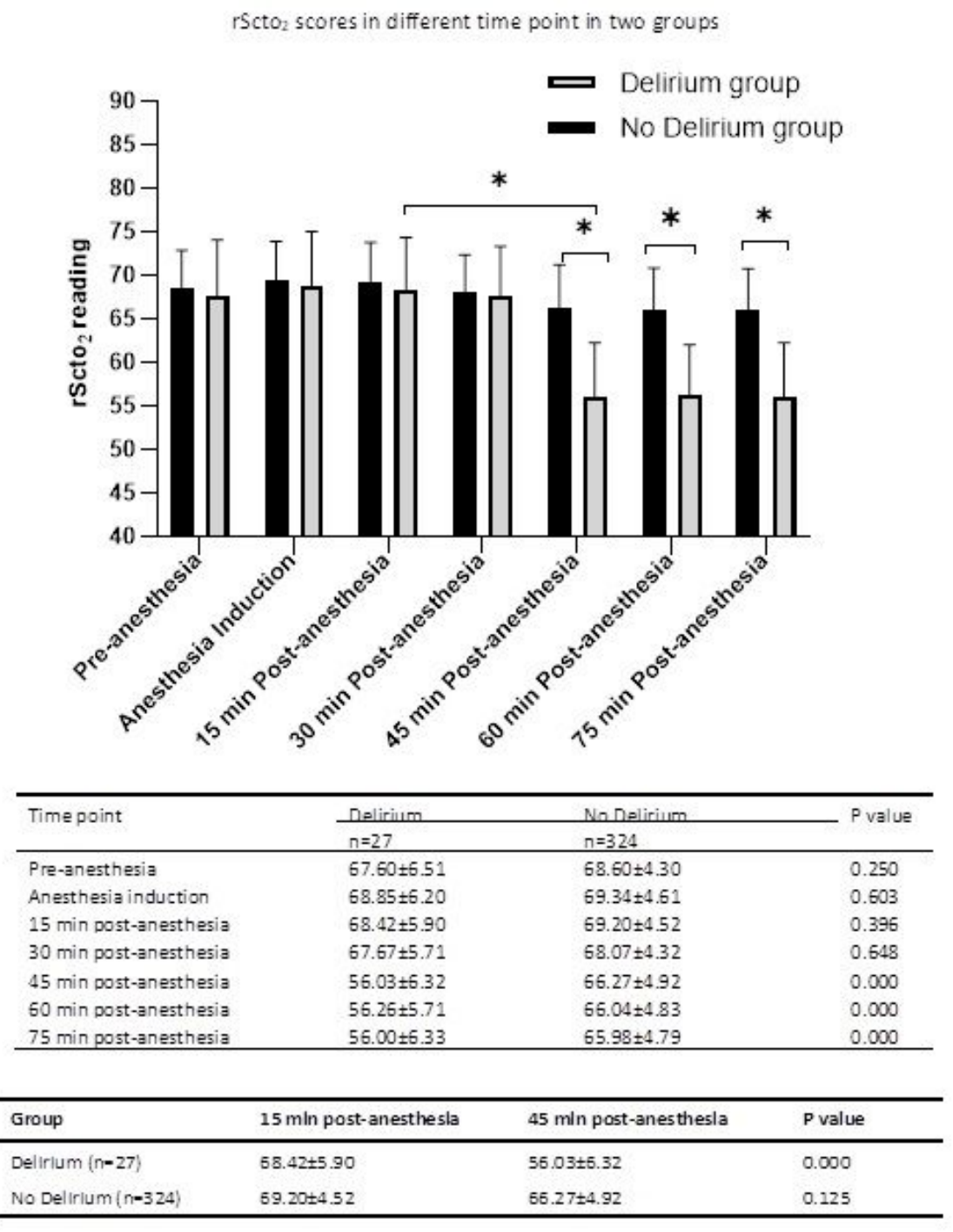

Figure 2

rSctO2 readings in different time point in two groups. Data are presented as mean ( \pm SD) (\%). 